\title{
SALDO DE RADIAÇÃO EM PLANTIOS DE EUCALIPTO EM ÁREAS DE RELEVO ONDULADO ${ }^{1}$
}

\author{
Alexandro Gomes Facco ${ }^{2}$, Aristides Ribeiro ${ }^{3}$, Gilberto Chohaku Sediyama ${ }^{3}$, Fernando Palha Leite ${ }^{4}$ e Nairam \\ Félix de Barros ${ }^{5}$
}

\begin{abstract}
RESUMO - O conhecimento detalhado de radiação solar total que incide sobre uma região é importante para o planejamento das atividades florestais. Poucos trabalhos têm considerado a topologia da região para determinar o saldo de radiação solar (Rn), o que pode levar a erros significativos de estimativa dessa variável, dependendo do tipo de relevo predominante na região. Este estudo teve como objetivo estimar o Rn em plantios de eucalipto, levando-se em consideração a exposição do terreno em plantios florestais de eucalipto, bem como comparar essas estimativas com a estimativa em condições de topografia plana. A simulação foi realizada para os anos de 2001 e 2002, em uma microbacia do rio Doce. As encostas com orientações para o norte, nordeste e noroeste apresentaram aumentos do Rn em relação à estimativa da superfície plana, pelo fato de que, nessa época do ano, o sol, em seu movimento aparente, encontra-se ao norte da microbacia. Entretanto, as encostas com orientações para o sul, sudeste e sudoeste tiveram diminuição do Rn quando comparadas com as condições de topografia plana. A inclinação das encostas influenciou a magnitude das diferenças de ganho e perda de Rn. Quanto maiores as inclinações das encostas voltadas para o norte, noroeste e nordeste, maiores as variações, atingindo valores percentuais de aumento do Rn de até $40 \%$, em julho. Portanto, verificou-se existir importante influência das diferentes inclinações e orientações das encostas nos totais diários do Rn.
\end{abstract}

Palavras-chave: Eucalipto, saldo de radiação e SIG.

\section{NET RADIATION FOR EUCALYPT PLANTATIONS IN AREAS WITH UNDULATED RELIEF}

\begin{abstract}
The detailed knowledge of the total solar radiation that reaches a surface is fundamental for the planning of the forest activities. A few research works cited in the literature have considered the topographic effect of the region to determine the solar radiation balance $(R n)$, in which, depending on the predominant topographic relief of the region, significant errors can be obtained. This study was carried out to estimate the $R n$ considering the slope aspect of the terrain for eucalypt forest plantation, and to compare this estimates with and flat terrain areas. The simulation was carried out for the years of 2001 and 2002 in Rio Doce watershed. The hillsides with northward, northeast and the northwest orientation presented increases in $R n$ in relation to the estimate for flat horizontal surface, because at this time of the year, the sun, in its apparent movement, tape place north of the watershed. However, the hillsides with south, southeast and southwest orientation, presented reduction in $R n$ when compared with the conditions of flat topography. The hillsides inclination influenced in the magnitude of the differences between gain of energies and loss $R n$. The hillsides inclinations faced northward, the northwest and northeast, had greaters variations, witch increased $R n$ of up to $40 \%$, in July. It was demonstrated that exist important influence of the different slopes and aspects of the hillsides terrain over the total daily radiation balance.
\end{abstract}

Keywords: Eucalypt, net radiation and GIS.

\footnotetext{
${ }^{1}$ Recebido em 09.08.2007 e aceito para publicação em 24.04.2009.

${ }^{2}$ Universidade Federal Rural do Rio de Janeiro (UFRRJ). E-mail: <agfacco@ gmail.com>.

${ }^{3}$ Departamento de Engenharia Agrícola da UFV. E-mail: <ribeiro@ufv.br>.

${ }^{4}$ Celulose Nipo Brasileira S A. E-mail: <fernando.leite@ cenibra.com.br>.

${ }^{5}$ Departamento de Solos da UFV. E-mail: <nfbarros@ufv.br>.
} 


\section{INTRODUÇÃO}

O saldo de radiação $(R n)$ representa a energia disponível para diversos processos físico-químicos que ocorrem na superfície e o principal parâmetro utilizado em muitos métodos que estimam evapotranspiração e fotossíntese em plantios de eucalipto. A quantificação das perdas de água para a atmosfera é um elemento muito valioso no planejamento de atividades florestais e no gerenciamento dos recursos hídricos de uma bacia hidrográfica. Portanto, para se obterem estimativas corretas de evapotranspiração, é muito importante ter-se o saldo de radiação medido ou estimado de forma correta e precisa.

A radiação solar global $(R g)$ é a quantidade de energia que chega à superfície da terra na forma de radiação de ondas curtas. A Rg é composta por dois componentes, o direto e o difuso. A radiação solar direta compreende a radiação que vem diretamente do disco solar. Essa componente depende, principalmente, das condições de céu limpo, localização geográfica da superfície de incidência dos raios solares, ângulo de incidência dos raios solares e da inclinação e orientação da superfície. (IQBAL et al., 1983). A literatura apresenta diversos modelos matemáticos como aqueles encontrados em, Iqbal, 1979; Erbs et al., 1982; Spencer, 1982; Jain, 1990; Hussain, 1992; Hinrichsen, 1994; Lima, 1996.

Poucos trabalhos citados na literatura têm considerado a topografia da região para determinar o saldo de radiação solar, o que, dependendo do tipo de relevo, pode acarretar em erros de estimativas (DUBAYAH e LOECHEL, 1997; OSOZAWA et al., 2002; MEFTI et al., 2003). Com o crescente desenvolvimento de sistemas de informações geográficas, a estimativa do saldo de radiação solar tem sido mais bem representada quando se consideram modelos matemáticos ou digitais do terreno da região estudada. A precisão espacial deve ser a maior possível, porém essa precisão está fortemente ligada ao tempo de computador necessário para os cálculos (FACCO, 2004)

Este estudo teve como objetivos estimar o saldo de radiação, levando-se em consideração a exposição do terreno em plantios de eucalipto, e comparar essa estimativa com aquela em condições de topografia plana.

\section{MATERIAL E MÉTODOS}

O estudo foi realizado em uma microbacia hidrográfica do rio Doce, localizada no Município de Belo Oriente, na região do Vale do Rio Doce, Estado de Minas Gerais, cujas coordenadas geográficas são latitude $19^{\circ} 21^{\prime}$ S e longitude $42^{\circ} 15^{\prime} \mathrm{O}$ (Figura 1a). Essa área é coberta com eucalipto plantado em 1998 e 1999 e por mata ciliar (Figura 1b). A topografia da região vai de plano a forte-ondulado, com altitude média de 248 m, inclinação média das encostas de $21 \%$ e orientações predominantes com face voltada para o sul e sudeste (Figura 2). Sua área de drenagem é de aproximadamente 364 ha. O período de estudo foi entre $1^{\circ}$ de janeiro de 2001 a 31 de dezembro de 2002. Os dados meteorológicos utilizados nas estimativas dos componentes do $R n$ foram coletados em escala horária de uma estação meteorológica automática localizada a $8 \mathrm{~km}$ da microbacia, com altitude de $324 \mathrm{~m}$. Essa estação meteorológica é de propriedade da empresa de celulose CENIBRA S.A. O modelo digital do terreno (MDT) tem resolução espacial de 16 por 16 m e precisão altimétrica de $10 \mathrm{~m}$. Pelo fato de a microbacia ser relativamente pequena, não foi considerada a esfericidade terrestre da superfície na determinação das áreas de sombreamento, e a latitude e longitude de cada célula do MDT foram iguais à latitude e longitude do centro dessa célula.

O $R n$ foi calculado em escala horária considerando a topologia da microbacia de estudo, e foram obtidos totais diários pela soma dos valores horários. Consideraram-se tanto as inclinações e as orientações das encostas quanto o sombreamento para o cálculo da energia diária em cada célula. O saldo de radiação foi estimado pelas equações de 1 a 20.

A $R g$ foi estimada usando-se a equação 1, proposta por Vianello (2002) e adaptada para considerar a influencia do sombreamento de uma célula do MDT em outra célula.

$$
\begin{aligned}
& R_{\mathrm{g}}=\mathrm{I}_{\mathrm{n}} \operatorname{Cos}(\theta) \operatorname{Somb}+\mathrm{D} \operatorname{Cos}^{2}\left(\frac{\mathrm{i}}{2}\right)+\alpha\left[\mathrm{I}_{\mathrm{n}} \operatorname{Cos}(\mathrm{Az})\right. \\
& +\mathrm{D}] \operatorname{Sen}^{2}\left(\frac{\mathrm{i}}{2}\right)
\end{aligned}
$$

em que: $R g$ = radiação solar global (MJm-2h-1); Somb = área com sombreamento (Booleano); $I n=$ radiação solar direta normal à superfície (MJm-2h-1); $D=$ radiação solar difusa $\left(\mathrm{MJm}^{-2} \mathrm{~h}^{-1}\right) ; \mathrm{q}=$ ângulo vertical de incidência dos raios solares diretos; $A z=$ azimute ou orientação da superfície (graus); $i=$ inclinação da superfície (graus) e $\mathrm{a}=$ albedo da superfície $(\mathrm{adm})$. 


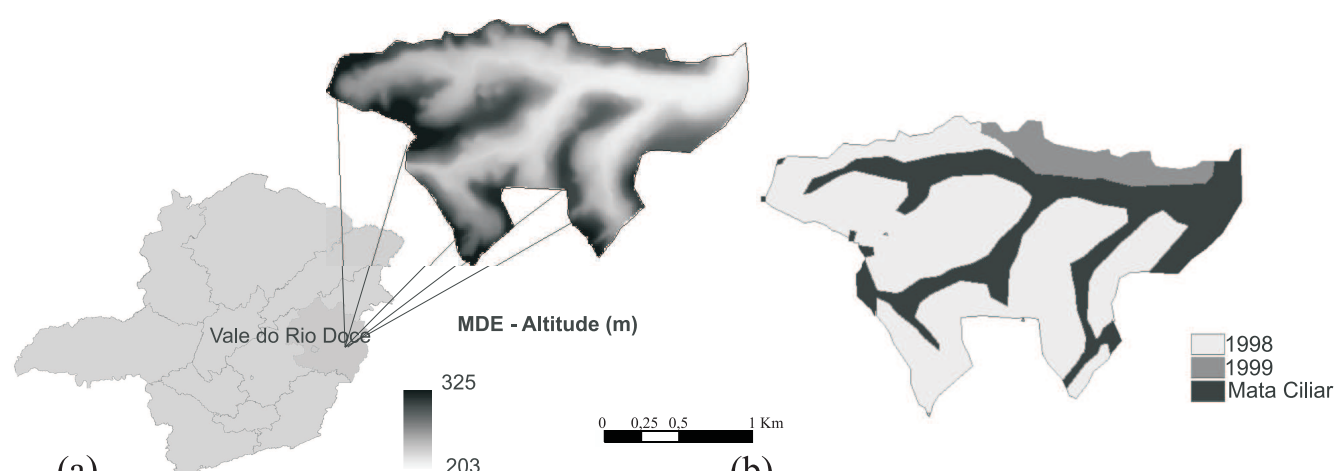

(a)

203

(b)

Figura 1 - (a) Localização e topografia da microbacia do rio Doce; e (b) espacialização do tipo de cobertura vegetal e data de plantio dos eucaliptos na microbacia.

Figure 1 - (a) Location and topography of the Doce River watershed; and (b) Spatialization of the vegetation type and eucalyptus plantation in the watershed.

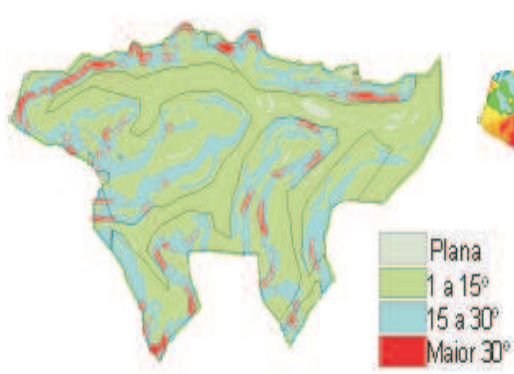

(a)
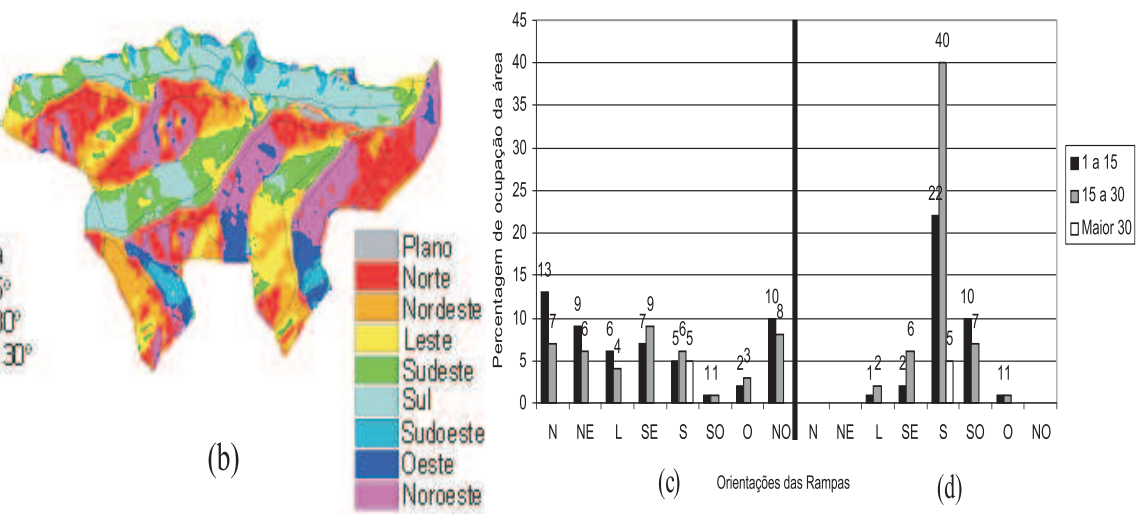

(c) Orientaçoes das Rampas

(d)

Figura 2 - Classes de inclinações (a) e orientações das encostas (b) na microbacia. Histograma de distribuição de frequência das inclinações e orientações das encostas, em função das áreas com plantio realizado em 1998 (c) e 1999 (d).

Figure 2 - Slope classification (a) and orientations $(b)$ in the watershed. Frequency distribution histogram of the slopes and aspects of the hillsides, according to the the areas planted with eucalyptus in 1998 (c), and 1999 (d).

$$
I_{n}=\frac{I_{d}}{\operatorname{Cos}(z)}
$$

em que $I d=$ radiação direta em superfície perpendicular aos raios solares $\left(\mathrm{MJm}^{-2} \mathrm{~h}^{-1}\right)$ e $\mathrm{z}=$ ângulo zenital (graus).

As variações interanuais das relações astronômicas foram desconsideradas por se entender que a sua influência é reduzida quando são considerados os modelos propostos e utilizados.

A estimativa da radiação solar difusa horária foi feita por meio do modelo matemático proposto por Lima (1996), desenvolvido para o Município de Viçosa, MG. Esse modelo é uma combinação de equações, considerando-se diferentes intervalos da relação da $R g$ e da radiação no topo da atmosfera $(R a)$.

$M=\frac{I_{d}}{R g}, M_{T}=\frac{R g}{R a}$

$M=1-0,221 M_{T} ;$ para $\mathrm{M}_{\mathrm{T}}=0,20$

$M=0,798+2,442 M_{T}-9,634 M_{T}^{2}+6,9381 M_{T}^{3}$; para $0,20>\mathrm{M}_{\mathrm{T}}=0,80$

$M=0,135 ; \operatorname{para} \mathrm{M}_{\mathrm{T}}>0,80$

O ângulo vertical de incidência dos raios solares diretos (q) foi estimado usando as equações 8 a 11 ,

R. Árvore, Viçosa-MG, v.33, n.3, p.471-480, 2009 
em que $h$ é o ângulo horário (graus); e $A, B$ e $C$, os parâmetros de simplificação da equação (IQBAL, 1983).

$$
\begin{aligned}
& \operatorname{Cos}(\theta)=\mathrm{A} \operatorname{Cos}(\mathrm{h})+\mathrm{B} \operatorname{Sen}(\mathrm{h})+\mathrm{C} \\
& A=\operatorname{Cos}(\varphi) \operatorname{Cos}(\delta) \operatorname{Cos}(\mathrm{i})+\operatorname{Sen}(\mathrm{i}) \operatorname{Cos}(\mathrm{Az}) \operatorname{Cos}(\delta) \operatorname{Sen}(\varphi) \\
& \mathrm{B}=\operatorname{Sen}(\mathrm{i}) \operatorname{Cos}(\delta) \operatorname{Sen}(\mathrm{a}) \\
& \mathrm{C}=\operatorname{Sen}(\varphi) \operatorname{Sen}(\delta) \operatorname{Cos}(\mathrm{i})-\operatorname{Sen}(\mathrm{i}) \operatorname{Cos}(\mathrm{Az}) \operatorname{Sen}(\delta) \operatorname{Cos}(\varphi)
\end{aligned}
$$

O balanço de ondas curtas (Boc) foi dado pela equação 18 :

$$
B o c=R_{g}(1-\alpha)
$$

Foram adotados valores de albedo variando em função da idade e do período seco e úmido do ano. Esses valores foram baseado-se em dados coletados nas áreas de plantio da Cenibra S.A., sendo no período seco 0,22, em plantas com as idades de 2 e 3 anos; 0,21 na idade de 4 anos; e no período chuvoso 0,16 , em plantas com as idades de 2 e 3 anos e 0,15 na idade de 4 anos.

Para estimar o balanço de ondas longas $(\mathrm{Bol}) \mathrm{em}$ plantios de eucalipto, foi proposto um modelo baseado no desenvolvido por Brunt (1932), considerando-se a pressão parcial de vapor em $\mathrm{mmHg}(e)$ e a temperatura média em ${ }^{\circ} \mathrm{C}\left(t_{\text {med }}\right)$. Para a geração desse modelo, foram utilizados dados coletados com sensor Kipp Zonen CNR1, durante seis meses, em plantios de eucalipto na região de Aracruz, ES.

Bol $=9,5035 \times 10^{-5} \cdot t_{\text {med }}{ }^{4} \cdot(0,09 \cdot \sqrt{e}-0,56)+0,456\left(\mathrm{r}^{2}\right.$ $=89 \%$ )

Finalmente, $R n$, em $\mathrm{MJ} \mathrm{m}^{-2} \mathrm{~d}^{-1}$, é dado pela seguinte equação:

$R_{n}=\mathrm{Boc}+\mathrm{Bol}$

A implementação do sistema foi feita utilizandose a linguagem de programação do software "Visual
Basic 6.0", que é processado no sistema de informações geográficas ArcGis 8.3 (ESRI), por meio de comandos automatizados (macros). Os cálculos dos componentes energéticos foram realizados em escala horária e integrados dia a dia. A estrutura do sistema desenvolvido pode ser visualizada no fluxograma da Figura 3. A partir do MDT, determinaram-se altitudes, sombreamentos, inclinações e orientações das encostas para cada célula. Associando os sombreamentos, inclinações e orientações das encostas aos dados meteorológicos, calculou-se o Rn em cada célula, em escala horária e integrado dia a dia.

\section{RESULTADOS E DISCUSSÃO}

Devido à localização geográfica da microbacia, o sol se posiciona ao norte a maior parte do ano, ficando ao sul apenas 70 dias do ano, entre os dias 16 de novembro e 24 de janeiro. Os modelos tridimensionais mostram a influência do posicionamento do sol no sombreamento da bacia nos dias de solstício de verão do hemisfério sul (22 de dezembro) e solstício de inverno (22 de junho) (Figura 4). No dia de solstício de verão, o relevo não proporcionou muitas áreas sombreadas, porque nesse dia o centro do sol, em seu movimento aparente, culminou ao meio-dia (tempo solar verdadeiro) a aproximadamente quatro graus ao sul da bacia. As maiores elevações do sol são verificadas nesse período do ano, o que garante maior disponibilidade de energia, atingindo valores máximos nos dias 16 de novembro e 24 de janeiro, quando a declinação solar é igual à latitude do local. A partir do dia 24 de janeiro, o centro do sol, em seu movimento aparente, culmina ao meio-dia (tempo solar verdadeiro), sempre ao norte da microbacia, tendo seu maior distanciamento no dia de solstício de inverno para o hemisfério sul (21 de junho). A partir dessa data, tem sua passagem aparente, durante os dias, cada vez menos ao norte até o dia 16 de novembro.

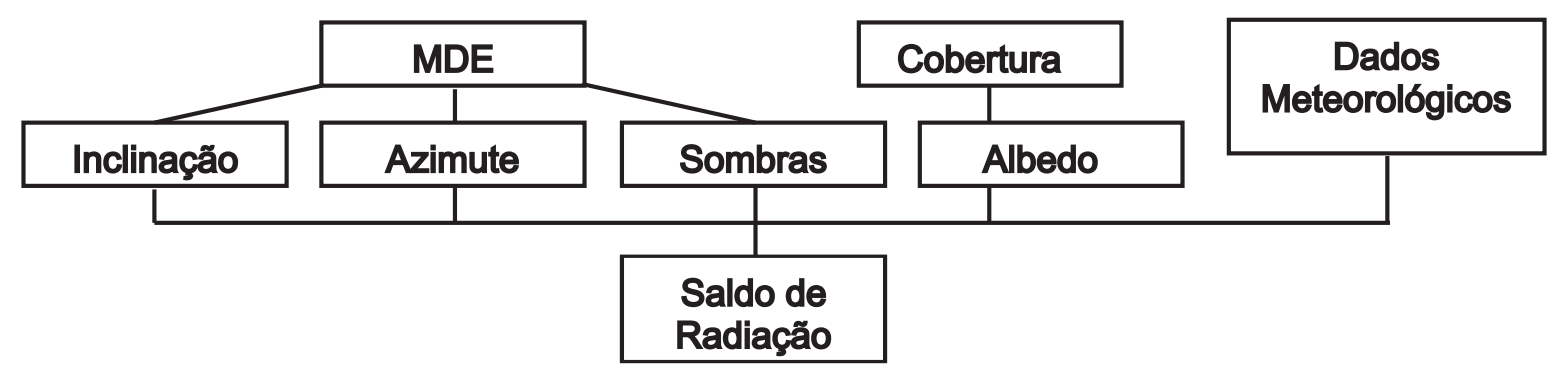

Figura 3 - Fluxograma do sistema desenvolvido para o balanço de radiação.

Figure 3 -Flowchart of the developed system for the radiation balance.

R. Árvore, Viçosa-MG, v.33, n.3, p.471-480, 2009 

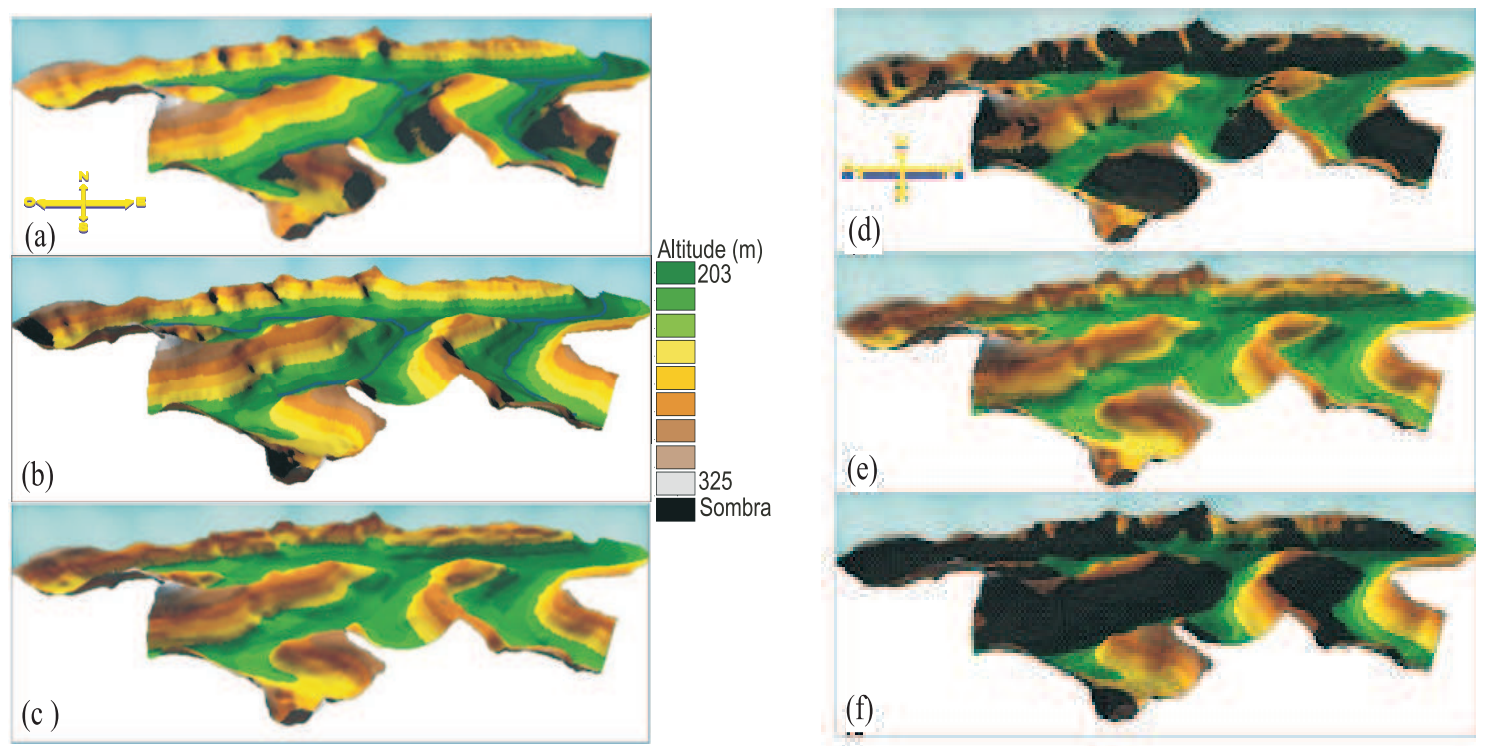

Figura 4 - Modelo tridimensional da representação da influência da posição solar no sombreamento da microbacia em 22 de dezembro: (a) 8 horas, (b) 12 horas e (c) 16 horas; e em 22 de junho: (d) 8 horas, (e) 12 horas e (f) 16 horas.

Figure 4-Three-dimensional model which represents the influence of the sun position in shading the watershed on December 22nd, (a) $8 \mathrm{am}$, (b) 12 (Noon), and (c) $4 \mathrm{pm}$; and June 22nd, (d) $8 \mathrm{am}$, (e) 12 (Noon), and (f) $4 \mathrm{pm}$.

Desde que não haja sombreamento do fluxo radiante no período do ano em que o sol está ao norte da microbacia, as encostas com faces de exposição orientadas para o norte, com inclinação igual à diferença entre a declinação solar e a latitude do local, terão a maior taxa energética. As encostas voltadas para o sul, com inclinação igual à diferença entre a declinação solar e a latitude do local, terão as menores taxas energéticas.

De forma geral, a topografia da microbacia teve influência importante no saldo de radiação, principalmente nos dias em que o sol se encontra mais ao norte da bacia, verificando-se as maiores amplitudes no saldo de radiação, quando comparadas as estimativas feitas para uma superfície plana. Resultados esses semelhantes ao encontrado por Lopes et al. (2003) na serra da Mantiqueira, onde observaram que a radiação solar direta ocorrida às 9 horas foi maior nas áreas com maiores altitudes e com rampas orientadas para o norte do que nas áreas mais baixas devido ao sombreamento gerado pelas encostas nas áreas baixas. E a radiação difusa foi maior nas áreas mais baixas.

A variação média mensal da radiação solar global, medida na estação meteorológica, pela manhã e pela tarde de cada dia, durante os dois anos estudados, mostra que, de forma geral, exceto nos meses de março, abril e maio de 2001, que a $R g$ de tarde foi superior as $R g$ ocorridas pela manhã (Figura 5). Esse fato pode ser explicado pela grande ocorrência de nevoeiros pela manhã nas áreas próximas à estação meteorológica. A ocorrência desses nevoeiros é devida à proximidade da área de estudo com o rio Doce.

A variação mensal do $R n$ de 2001 e 2002 mostra que nos meses de janeiro, fevereiro, junho e setembro de 2001 seus valores foram estimados como superiores aos estimados nos mesmos meses do ano de 2002. Entretanto, os meses de março, abril, maio, junho, outubro e dezembro apresentaram valores superiores de $R n$ estimado nos mesmos meses, no ano de 2001 (Figura 6).

Os meses de agosto e novembro apresentaram valores semelhantes entre si. Essas variações estão fortemente ligadas às durações das precipitações ocorridas nos dois anos. No mês de janeiro de 2001, por exemplo, ocorreram precipitações durante $12 \mathrm{~h}$, enquanto em janeiro de 2002 foram 89 h com ocorrência de precipitações.

R. Árvore, Viçosa-MG, v.33, n.3, p.471-480, 2009 


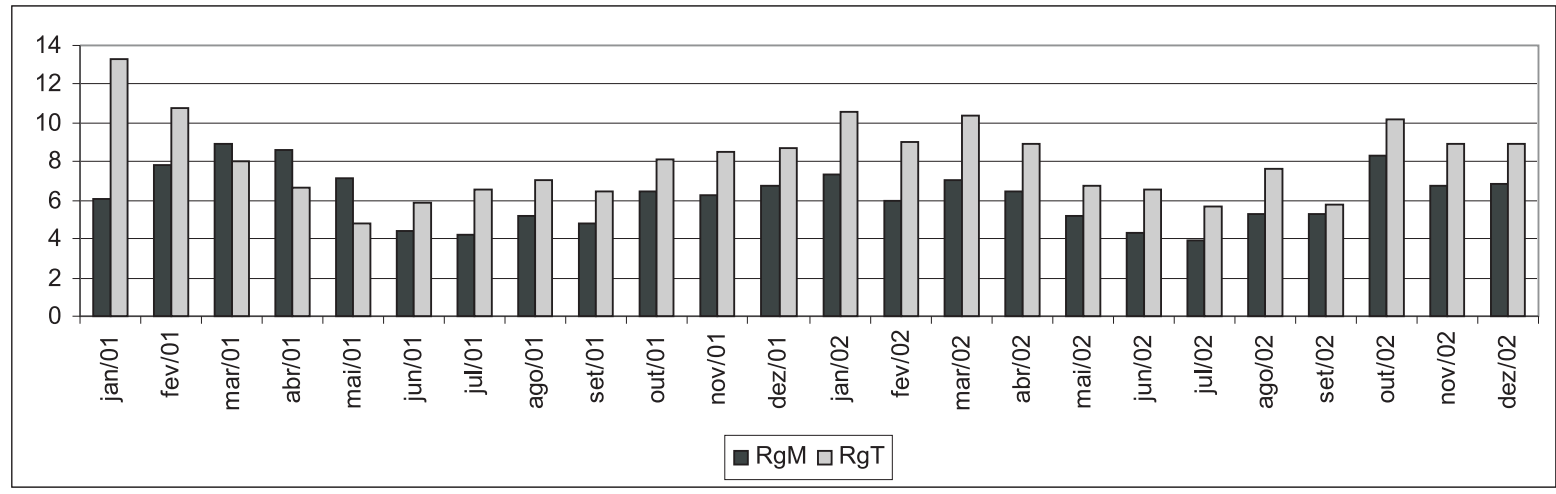

Figura 5 - Variação mensal dos totais médios da radiação solar global $(R g)$, medida pela manhã $(R g M)$ e à tarde $(R g T)$, de cada dia na estação meteorológica, durante o período de estudo, $\mathrm{MJm}^{-2}$.

Figure 5 -Monthly variation of the total global average solar radiation ( $R g)$ measured in the morning ( $R g M)$ and in afternoon $(\operatorname{Rg} T)$, at the meteorological station, every day, during the study period, $\mathrm{MJm}^{-2}$.

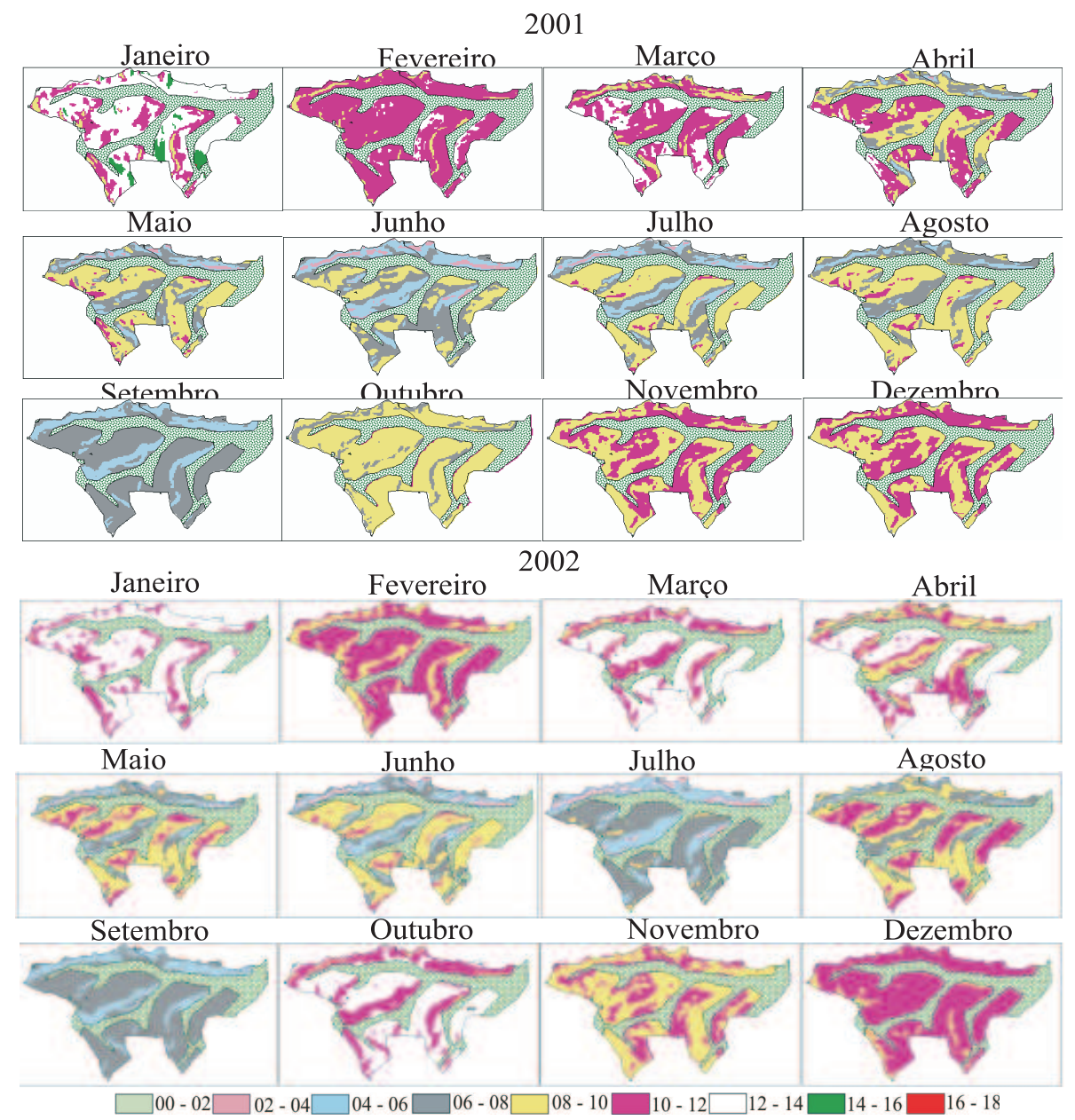

Figura 6 - Espacialização do saldo de radiação diária $\left(\mathrm{MJm}^{-2} \mathrm{~d}^{-1}\right)$ nos meses de janeiro a dezembro dos anos de 2001 e 2002. Figure 6 - Spatialization of the daily net solar radiation $\left(\mathrm{MJm}^{-2} \mathrm{~d}^{-1}\right)$, from January to December 2001 and 2002.

R. Árvore, Viçosa-MG, v.33, n.3, p.471-480, 2009 
Nos dois anos de estudo, o mês de janeiro apresentou maiores valores de $R n$, sendoem janeiro de 2001 as superfícies com encostas voltadas para oeste e com inclinações mais suaves apresentaram valores entre 14 e $18 \mathrm{MJ} \mathrm{m}^{-2} \mathrm{~d}^{-1}$. Os meses de maio, junho e julho apresentaram os menores valores de $R n$. Normalmente, o valor do $R n$ é inferior nos demais meses do ano, em regiões localizadas no hemisfério sul do planeta, devido à posição aparente do sol, que está ao norte do hemisfério sul em sua trajetória aparente. Entretanto, a topografia da microbacia favoreceu o aumento das diferenças entre os ganhos e as perdas do $R n$. As

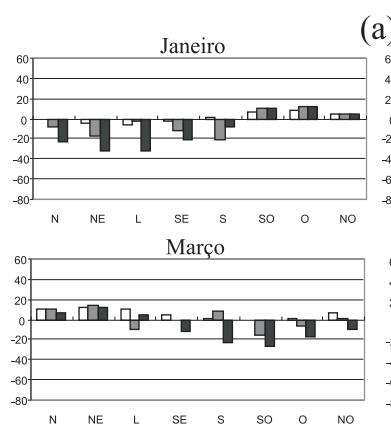

(a)

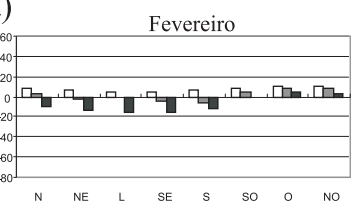

Abril
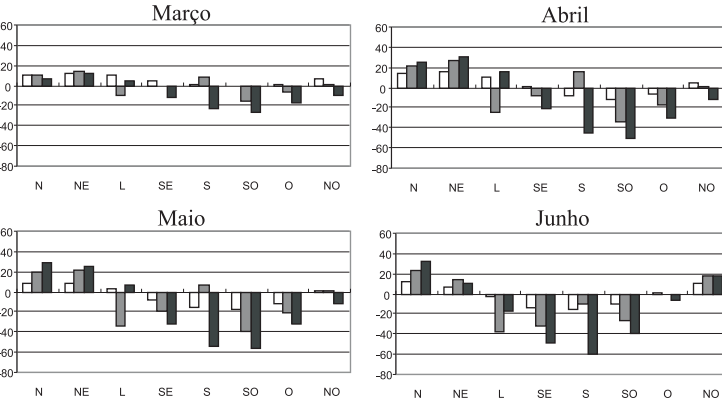

Julho
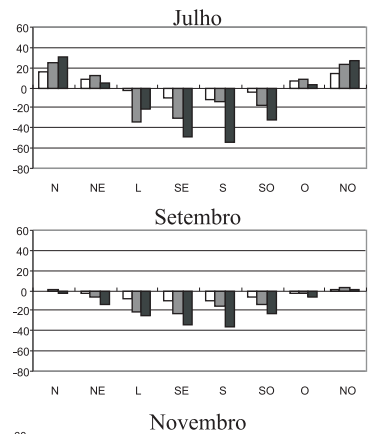

Novembro

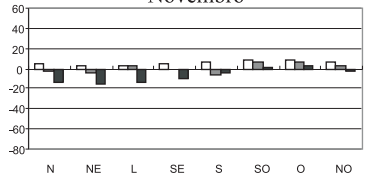

Agosto

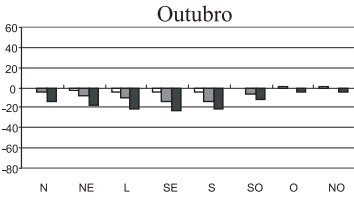

Dezembro regiões com encostas voltadas para o sul e com maiores inclinações foram as que obtiveram os menores valores, enquanto as regiões com encostas voltadas para o norte e com inclinações maiores obtiveram os maiores valores de $R n$.

Para mostrar a importância da inclinação e da face de exposição original do terreno na estimativa do $R n$, as Figuras 7 e 8 apresentam as diferenças (ganhos e perdas) entre o $R n$ estimado considerando a topografia original e o $R n$ considerando a superfície como plana,

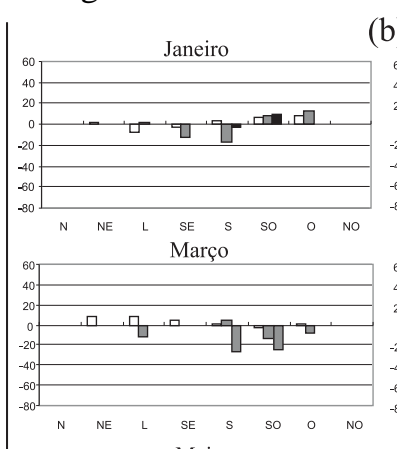

(b)
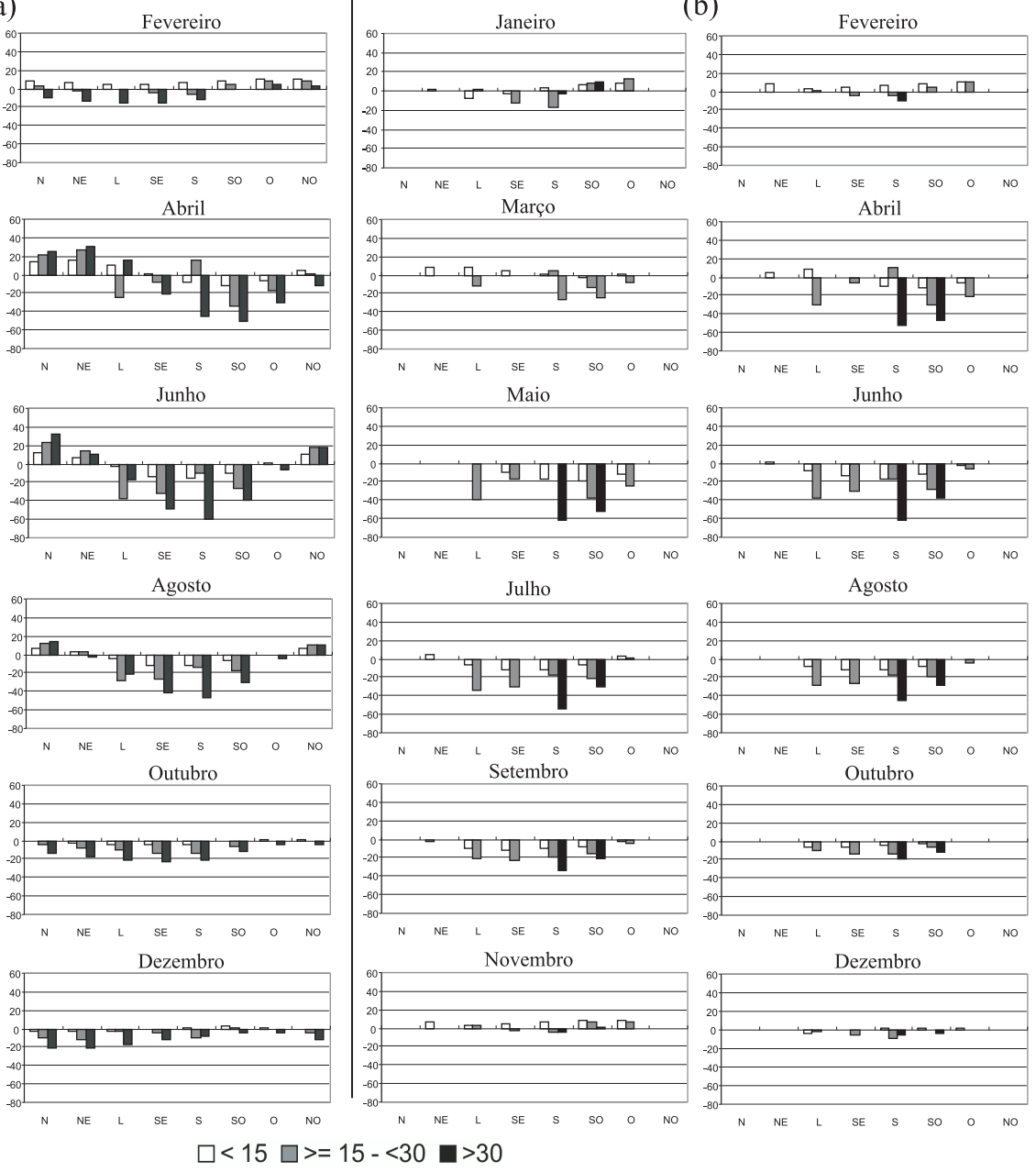

Figura 7 - Histograma de frequência das diferenças (ganhos e perdas) entre o $R n$ estimado-se a topografia original e o $R n$ considerando-se a superfície como plana, em diferentes classes de graus de inclinações e diferentes faces de orientações das encostas. Aqui são apresentadas as variações entre os diferentes meses do ano de 2001, nas áreas com plantios de 3 anos de idade (1998) (a) e nas áreas com plantios de 2 anos de idade (1999) (b).

Figure 7 - Frequency histogram of the differences (gains and losses) between the estimated Rn considering the original topography, and the Rn considering the flat surface, for different degrees of slope classes and different aspect azimuths. The variations among different months of the year 2001 are presented here in the areas with 3-yearold plantations (1998) (a) and in the areas with 2-year-old plantations (1999) (b). 
nos dois anos estudados (2001 e 2002) e nas duas datas de plantios (1998 e 1999). Os meses de abril a setembro apresentaram as maiores diferenças entre as duas condições de topografia (original e plana), em todas as idades e anos estudados. As encostas com orientações para o norte, nordeste e noroeste apresentaram aumentos do $R n$ em relação à estimativa da superfície plana, pelo fato de que, nessa época do ano, o sol, em seu movimento aparente, encontra-se ao norte da microbacia.
Entretanto, as encostas com orientações para o sul, sudeste e sudoeste apresentaram perdas de $R n$ quando comparadas com as condições de topografia original e com as de topografia plana. As encostas com orientações voltadas para o leste apresentaram comportamentos diferentes das encostas voltadas para o oeste, pelo fato de a $R g$, registrada no período da tarde, ter sido superior à $R g$, registrada pela manhã.
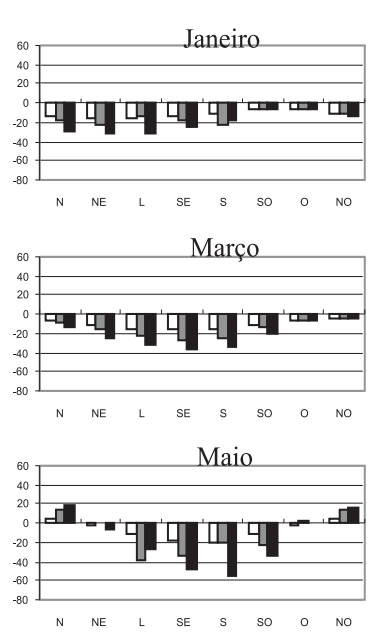

Julho

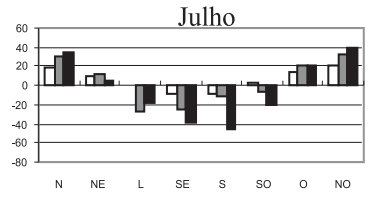

Setembro

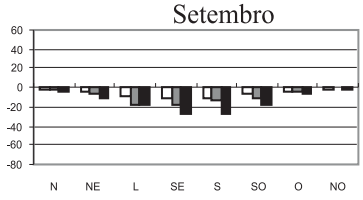

Novembr

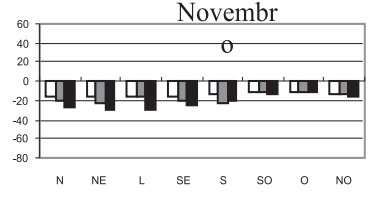

(a)
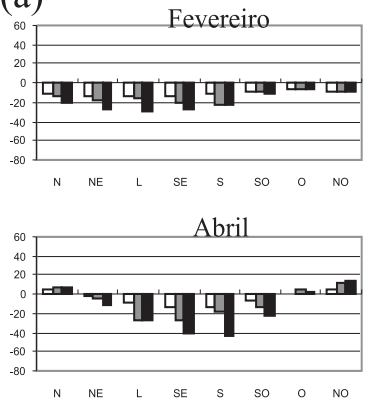

Junho

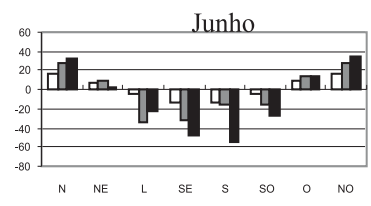

Agosto

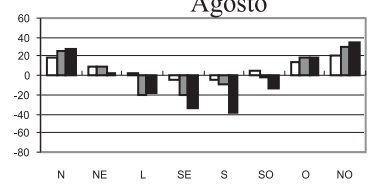

Outubro

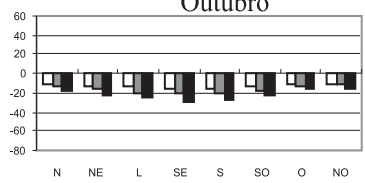

Dezembr

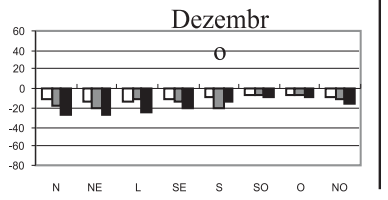

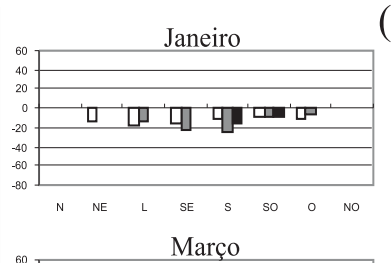

(b)
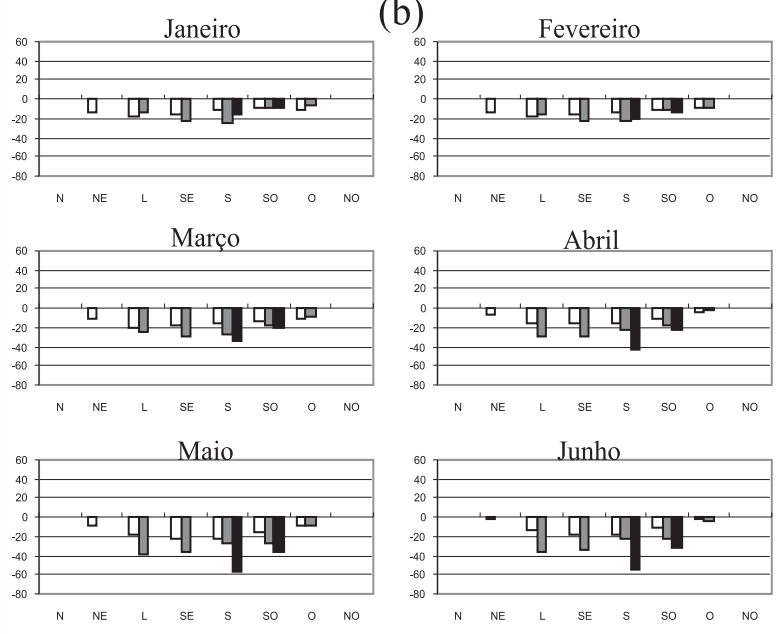

Agosto
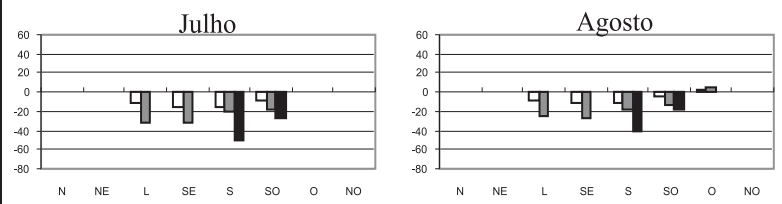

Setembro
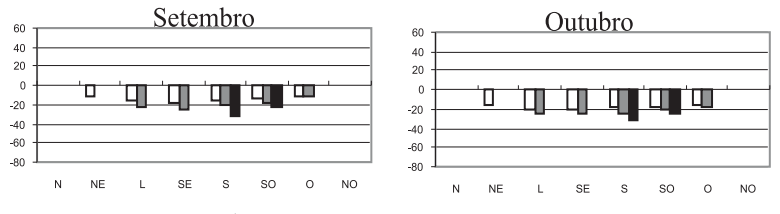

Novembr
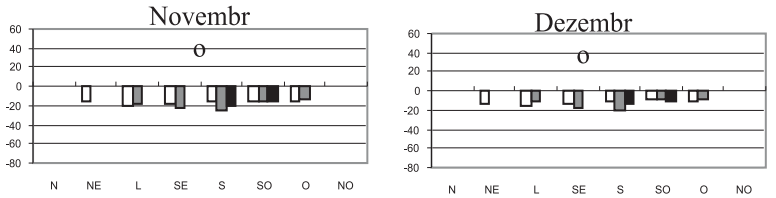

$\square<15 \square>=15-<30 \square>30$

Figura 8 - Histograma de frequência das diferenças (ganhos e perdas) entre o Rn estimado considerando-se a topografia original e o Rn considerando-se a superfície como plana, em diferentes classes de graus de inclinações e diferentes faces de exposição do terreno. Aqui são apresentadas as variações entre os diferentes meses do ano de 2002 nas áreas com plantios de 4 anos de idade (1998) (a) e nas áreas com plantios de 3 anos de idade (1999) (b).

Figure 8 -Frequency histogram of the differences (gains and losses) between the estimated Rn considering the original topography and the Rn considering the flat surface, for different degrees of slope classes, and different aspect azimuths. The variations among different months of the year 2001 are presented here, in the areas with 4-yearold plantations (1998) (a) and in the areas with 3-year-old plantations (1999) (b).

R. Árvore, Viçosa-MG, v.33, n.3, p.471-480, 2009 
A inclinação das encostas influenciou a magnitude das diferenças de ganho e perda de $R n$. Quanto maiores as inclinações das encostas voltadas para o norte, noroeste e nordeste, maiores foram as variações, atingindo valores percentuais de aumento do $R n$ de até $40 \%$, no mês de julho de 2001, nas áreas com plantio de 1998 (Figura 8). Seguindo comportamento inverso, as encostas voltadas para o sul e com maiores inclinações apresentaram as maiores reduções, atingindo valores de até $70 \%$, no mês de maio de 2001, nas áreas com plantio de 1999. Esses resultados seguem a mesma tendência dos obtidos por Alves (1981), quando estimou a $R g$ para superfícies inclinadas no Município de Viçosa, MG.

Nos meses de outubro a março, a orientação da face das encostas não influenciou, de forma significativa, os valores de $R n$. O fator que mais influenciou foi a inclinação das encostas. Notou-se que, quanto maior a inclinação, maiores foram as diferença dos ganhos e perdas de $R n$, chegando a valores máximos de $25 \%$ em dezembro e janeiro, meses em que a trajetória aparente do sol atingiu a maior elevação em relação à localização da microbacia.

A importância do sombreamento indica tendência de ganho de radiação nas encostas voltadas para o leste nos meses 4 e 5 (Figura 8). No entanto, conforme é apresentado nessa figura, as rampas com essa orientação e inclinação entre 15 e 30 graus sofreram redução, explicada pela predominância de sombreamento nas áreas com essa orientação e inclinação.

\section{CONCLUSÕES}

Verificou-se existir importante influência das diferentes inclinações e orientações das encostas nos totais diários do saldo de radiação. Devido à posição geográfica e às características da topografia da bacia, o saldo de radiação não sofreu grandes alterações no verão. Porém, no inverno, quando o sol está mais ao norte da microbacia, essa diferença chegou até -50\% nas encostas voltadas para o sul e sofreu aumento de $20 \%$ nas regiões com encostas voltadas para o norte. Assim, verificou-se ser importante, nas regiões de relevo fortemente ondulado, fazer a correção espacial da intensidade de fluxo, a partir da radiação solar medida no piranômetro.

A precisão altimétrica do MDT utilizado foi satisfatória nas condições de topografia dessa área de estudo, porém em regiões de relevo mais ondulados é recomendado trabalhar com escala ainda maior.
Este estudo propôs metodologia para a determinação do saldo de radiação espacial em plantios de eucalipto, o que favorece melhor estimativa da demanda de água pela planta e, consequentemente, a determinação de áreas com maior ou menor potencial para cultivo do eucalipto.

\section{REFERÊNCIAS}

ALVES, A. R. Irradiância solar global em superfície de diferentes inclinações e azimutes, para Viçosa MG. 1981. 19f. Dissertação (Mestrado emMeteorologia Agrícola) Universidade Federal de Viçosa, Viçosa-MG, 1981.

BRUNT, D. Notes on radiation in the atmosphere. Quarterly Journal Royal Meteorology Society, v.58, p.389-418, 1932.

ERBS, D. G.; KLEIN, S. A.; DUFFIE, J. A. Estimation of the diffuse radiation fraction for hourly, daily na monthly; average global radiation. Solar Energy, v.28, n.4, p.293-302, 1982.

FACCO, A. G. Modelagem e simulação geoespacial dos componentes do balanço hídrico para plantios de eucalipto em áreas de relevo ondulado. 2004. 87f. Dissertação (Mestrado em Metereologia Agrícola) - Universidade Federal de Viçosa, Viçosa-MG, 2004.

HINRICHSEN, K. The Ângtron formula with coefficients having a physical meaning. Solar Energy, v.52, n.6, p.491-495, 1994.

HUSSAIN, M. Correlating beam radiation with sunshine duration. Solar Energy, v.48, n.3, p.145-149, 1992.

IQBAL, M. Correlation of overage diffuse and beam radiation with hours of bright sunshine. Solar Energy, v.23, n.2, p.169-173, 1979.

IQBAL, M. An introduction to solar radiation. New York: Academic Press, 1983.

JAIN, P. C. A model for diffuse and global radiation on horizontal surfaces. Solar Energy, v.45, n.5, p.301-308, 1990.

LIMA, F. Z. Desenvolvimento e avaliação de modelos de irradiância solar difusa para Viçosa - MG. 1996. 65p. Dissertação (Mestrado em Agronomia) - Universidade Federal de Viçosa, Viçosa-MG, 1996.

R. Árvore, Viçosa-MG, v.33, n.3, p.471-480, 2009 
LOPES, P. M. O.; SILVA, B. S.; VALERIANO, D. M. Modelagem de processos de ecossistemas em região montanhosa: variabilidade espacial da irradiância. In: SIMPÓSIO BRASILEIRO DE

SENSORIAMENTO REMOTO, 11., 2003, Belo Horizonte. Anais... Belo Horizonte: INPE, 2003. p.1347-1351.

MEFTI, A.; BOUROUBI, M. Y.; ADANE, A.

Generation of hourly solar radiation for inclined surfaces using monthly mean sunshine duration in Algeria. Energy conversion and

Management, v.44, n.19, p.3125-3141, 2003.
OSOZAWA, J.; KANO, H.; TATEISHI, R. Estimation of solar radiation using GMS and DEM data for determination of suitable agricultural land. Chiba: Center for Environmental Remote Sensing, Chiba University, 2002

SPENCER, J. W. A compararison of methods for estimating hourly solar radiation from global solar radiation. Solar Energy, v.29, n.1, p.19-32, 1982.

VIANELlO, R. L.; ALVES, A. R.; Meteorologia básica e aplicada. Viçosa, MG: Universidade Federal de Viçosa, 2002. p.133-203. 